\title{
Scutellaria barbata D. Don polysaccharides inhibit the growth of Calu-3 xenograft tumors via suppression of the HER2 pathway and angiogenesis
}

\author{
JUNFENG YANG, GUANGYU YANG, GUANGJIE HOU, QINGFENG LIU, WEICAI HU, PU ZHAO and YI HE \\ Department of Thoracic Surgery, People's Hospital of Henan Province, Zhengzhou, Henan 450003, P.R. China
}

Received June 2, 2014; Accepted March 2, 2015

DOI: $10.3892 / \mathrm{ol} .2015 .3127$

\begin{abstract}
Scutellaria barbata D. Don, a perennial herb belonging to the family Lamiaceae, is widely distributed throughout China and the Republic of Korea, and has been traditionally used in folk medicine as an antitumor and anti-inflammatory agent. Polysaccharides isolated from Scutellaria barbata D. Don (PSB), have been reported to possess antitumor effects. However, the detailed antitumor mechanisms behind the effects of PSB remain unclear. In the present study, a non-small cell lung cancer cell line harboring the HER 2 gene mutation Calu-3, the Calu-3 cell line, was used to investigate the underlying mechanisms of the antitumor effects of PSB. The results revealed that PSB potently inhibited cell proliferation and human epidermal growth factor receptor (HER)2 phosphorylation in vitro, and also downregulated the expression of the downstream signaling molecules, including phosphorylated (phospho-)Akt and phospho-extracellular signal-related kinase. In vivo, PSB demonstrated efficacy at well-tolerated doses, including significant antitumor activity in a Calu-3 subcutaneous xenograft model. Immunohistochemistry (IHC) analysis revealed a PSB dose-dependent reduction of microvessel density, demonstrated by cluster of differentiation 31 staining. The present findings suggest that inhibition of tumor angiogenesis via suppression of the HER2 pathway may be one of the mechanisms by which PSB can be effective in the treatment of cancers.
\end{abstract}

\section{Introduction}

The human epidermal growth factor receptor (HER) family consists of HER1, HER2, HER3 and HER4. The HER proteins form hetero- and homodimers that activate signal transduction

Correspondence to: Mr. Yi He, Department of Thoracic Surgery, People's Hospital of Henan Province, 7 Weiwu Road, Zhengzhou, Henan 450003, P.R. China

E-mail: yihe1989@126.com

Key words: Scutellaria barbata D. Don polysaccharides, human epidermal growth factor receptor 2, Calu-3, non-small cell lung cancer, Traditional Chinese Medicine pathways to regulate numerous cellular processes, including the growth, proliferation and survival of cells (1). Therefore, the HER proteins have been considered to be involved in oncogenesis (2). Tumors that overexpress the HER2 protein or exhibit amplification of the HER2 gene, in particular, are associated with aggressive disease progression and a poor prognosis $(3,4)$. HER 2 receptor overexpression occurs in $11-32 \%$ of non-small cell lung cancer (NSCLC) tumors, with an increased gene copy number documented in $2-23 \%$ of cases (5).

Worldwide, lung carcinoma is one of the leading causes of cancer-associated mortality in males and females (6). NSCLC accounts for $\leq 80 \%$ of all lung cancer cases. Patients have typically developed advanced disease by the time of diagnosis. The prognosis of patients with advanced lung cancer remains poor, and previous studies have indicated that conventional therapies may have reached a therapeutic plateau, as demonstrated by the five-year survival rate for NSCLC patients, which remains at $15 \%(7,8)$. These issues highlight the urgent requirement for the development of novel cancer chemotherapies. Recently, natural products, including those used in Traditional Chinese Medicine (TCM), have received interest as they result in relatively few side-effects and have been used clinically as alternative remedies for a variety of diseases for thousands of years $(9,10)$. Scutellaria barbata $\mathrm{D}$. Don, a perennial herb belonging to the family Lamiaceae, is widely distributed throughout China and the Republic of Korea, and has been traditionally used in folk medicine as an antitumor and anti-inflammatory agent $(11,12)$. It has been reported that polysaccharides isolated from Scutellaria barbata D. Don (PSB) possess antitumor activity that suppresses the growth of numerous types of cancer in vitro and in vivo $(13,14)$. To further elucidate the mechanism of the antitumor activity of PSB, the present study investigated its antitumor activity in vivo as well as the inhibitory effect of PSB on the HER2 pathway.

\section{Materials and methods}

Drug isolation and cell line. Scutellaria barbata D. Don was purchased from the Zhengzhou Market of Traditional Chinese Herbs (Chengdong Road, Zhengzhou, China) and was identified by Professor Yunzhi Du of Henan University of Traditional Chinese Medicine (Zhengzhou, Henan, China). PSB was prepared using the method described previously by Song et al (15). The dried and crushed Scutellaria barbata 
D. Don was extracted four times by decoction at $90^{\circ} \mathrm{C}$ using deionized water, with each extraction period lasting $2 \mathrm{~h}$. Subsequent to filtration, the resulting extract was mixed with four volumes of dehydrated ethanol, with the ethanol final concentration being $80 \%$, and incubated overnight at $4{ }^{\circ} \mathrm{C}$ in a refrigerator. Subsequently, the mixture was centrifuged at $3,618 \times \mathrm{g}$ for $10 \mathrm{~min}$, washed four times using dehydrated ethanol, and the precipitate was collected as crude PSB. Diethylaminoethyl-52 column chromatography (Whatman International Ltd., Maidstone, UK) was then used to purify the crude PSB, using $\mathrm{NaCl}$ solution at a concentration of $0.2 \mathrm{~mol} / \mathrm{l}$.

The Calu-3 cell line is a lung adenocarcinoma cell line in which HER2 is amplified to an average copy number of 30 (16). The cells were obtained from the American Type Culture Collection (Manassas, VA, USA) and cultured in RPMI-1640 medium supplemented with $10 \%$ fetal bovine serum (FBS). The cells were maintained at $37^{\circ} \mathrm{C}$ in a $5 \%$ $\mathrm{CO}_{2}$ humidified atmosphere. The RPMI-1640 medium and FBS were purchased from Invitrogen (Carlsbad, CA, USA). Trastuzumab (Herceptin; Genentech, Inc., San Francisco, CA, USA) was used as a positive control.

Cell growth inhibition assay. Cell growth inhibition was measured using the MTT dye reduction method. The Calu-3 cells in RPMI-1640 medium supplemented with $10 \%$ FBS were plated at a density of $1 \times 10^{4}$ cells $/ 100 \mathrm{ml} /$ well into 96-well plates and cultured with $10,20,40$ and $80 \mu \mathrm{g} / \mathrm{ml}$ of PSB or $10 \mu \mathrm{g} / \mathrm{ml}$ Herceptin for $72 \mathrm{~h}$, followed by the addition of $50 \mathrm{ml} \mathrm{MTT}$ solution (2 mg/ml; Sigma-Aldrich, St. Louis, MO, USA) to each well and further incubation for $2 \mathrm{~h}$. The medium was removed, and the dark blue crystals in each well were dissolved in $100 \mathrm{ml}$ dimethyl sulfoxide (Sigma-Aldrich). The percentage of cell growth inhibition was calculated as follows:

$$
\text { Cell growth inhibition }(\%)=\frac{A_{492 \text { vehicle }}-A_{492 \text { treatment }}}{x} 100
$$

$$
\mathrm{A}_{\text {vehicle492 }}
$$

where $\mathrm{A}_{492 \text { vehicle }}$ was the absorbance of the vehicle treatment [treated with phosphate buffered saline (PBS)] at $492 \mathrm{~nm}$ and $\mathrm{A}_{492}$ treatment was the absorbance of the experimental group (treated with PSB or Heceptin) at $492 \mathrm{~nm}$.

Western blot analysis. The Calu-3 cells were treated with various concentrations of PSB for $24 \mathrm{~h}$, and the cells were then lysed in cell lysis buffer containing phosphatase and proteinase inhibitor cocktails (Sigma-Aldrich). The protein concentrations were determined using a bicinchoninic acid protein assay kit (Pierce Biotechnology, Rockford, IL, USA). Equal amounts of protein $(50 \mu \mathrm{g})$ were separated by SDS/PAGE on $8 \%$ gels, blotted on polyvinylidene difluoride membranes (Bio-Rad Laboratories, Hercules, CA, USA), and probed with phosphorylated (p-)HER2, p-Akt, p-extracellular signal-regulated kinase (ERK), HER2, Akt and ERK rabbit monoclonal antibodies (catalog nos. 9923, 8609, 9271, 9272, 9101 and 9101, respectively; all purchased from Cell Signaling Technology, Danvers, MA, USA; dilution, 1:1000 with PBS), and subsequently with goat anti-rabbit horseradish peroxidase-conjugated secondary antibody, which was detected by chemiluminescence. The antibodies were purchased from Santa Cruz Biotechnology, Inc. (Dallas, TX, USA).

In vivo studies. Athymic BALB/c nu/nu male mice with an initial body weight of 20-22 g were obtained from Shanghai Laboratory Animal Center Laboratory Animal Co., Ltd. (Chinese Academy of Sciences, Shanghai, China) and housed under pathogen-free conditions with a $12 \mathrm{~h}$ light/dark cycle. Food and water were provided ad libitum throughout the experiment. In total, $5 \times 10^{6}$ Calu-3 cells per mouse were injected subcutaneously into mouse flanks. The tumor volumes were measured in two dimensions, the length and width, using calipers prior to treatment and twice a week once the treatment was initiated. The mice were also weighed at these times. The tumor sizes were calculated using the standard formula, as follows: tumor size $=\left(\right.$ length $\mathrm{x}$ width $\left.{ }^{2}\right) / 2$. Mice that developed tumors $150-200 \mathrm{~mm}^{3}$ in size were randomly allocated into the following four treatment groups, with eight mice in each group: Control, normal saline administered intraperitoneally once daily; $30 \mathrm{mg} / \mathrm{kg}$ Herceptin administered intraperitoneally twice a week; $100 \mathrm{mg} / \mathrm{kg}$ PSB administered intraperitoneally once daily; and $200 \mathrm{mg} / \mathrm{kg}$ PSB administered intraperitoneally once daily. The treatment regimen continued for 21 days and the mice were sacrificed $3 \mathrm{~h}$ subsequent to the last treatment. The tumors were excised and fixed overnight in $4 \%$ formalin, at $4^{\circ} \mathrm{C}$. The samples were then embedded in paraffin for immunohistochemical analysis. All animal experiments were performed in accordance with protocols approved by the Experimental Animal Center of the Henan University of Traditional Chinese Medicine Animal Care and Use Committee.

Immunohistochemistry analysis. The tumor specimens were fixed in $4 \%$ formalin for $24 \mathrm{~h}$ prior to being transferred to $70 \%$ ethanol. The tumor samples were subsequently embedded in paraffin, and $4-\mu \mathrm{m}$ thick sections were cut and baked at $58^{\circ} \mathrm{C}$ overnight, then placed onto microscope slides. The slides were successively incubated with the primary and secondary antibodies described in the western blot analysis section as wel as primary CD31 monoclonal antibody (catalog no. 3528; Cell Signaling Technology; dilution, 1:1000 with PBS), and visualized using a colorimetric method (DAB kit; Envision-HRP, Dako North America, Inc., Carpentaria, CA, USA). All immunostained sections were counterstained using hematoxylin. An automated Ventana Discovery XT Staining Module (Ventana Medical Systems, Inc., Tucson, AZ, USA) was used to conduct histological staining. The stained sections were analyzed using an Olympus BX60 microscope (Olympus Corporation, Tokyo, Japan) and quantitative analysis of section staining was performed using the Automated Cellular Imaging System (Clarient, Inc., Aliso Viejo, CA, USA). For the quantification of vascular area in lung tumors, up to four random fields for each tumor section at x100 magnification $(60 \%$ center field) were captured subsequent to staining with anti-cluster of differentiation (CD)31 antibody. The vascular area was calculated using Image Pro software (Media Cybernetics, Warrendale, PA, USA).

Statistical analysis. All data were reported as the mean \pm standard deviation for the indicated number of independently 


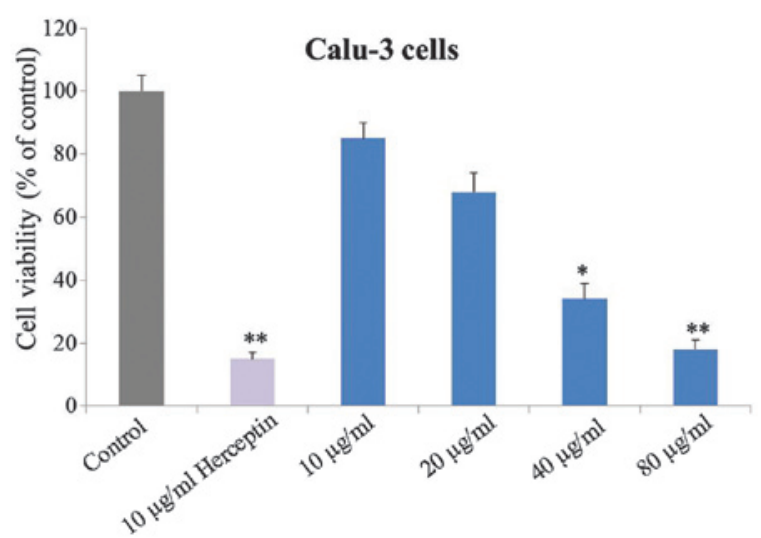

Figure 1.PSB dose-dependently inhibited Calu- 3 cell growth. The Calu- 3 cells were treated with $10,20,40$ and $80 \mu \mathrm{g} / \mathrm{ml}$ PSB for $72 \mathrm{~h}$. For the positive control, $10 \mu \mathrm{g} / \mathrm{ml}$ Herceptin was administered. The results are presented as the mean \pm standard deviation. $\mathrm{n}=3 ;{ }^{*} \mathrm{P}<0.05$ vs. control group; ${ }^{* *} \mathrm{P}<0.01$ vs. control group. PSB, polysaccharides isolated from Scutellaria barbata D. Don.

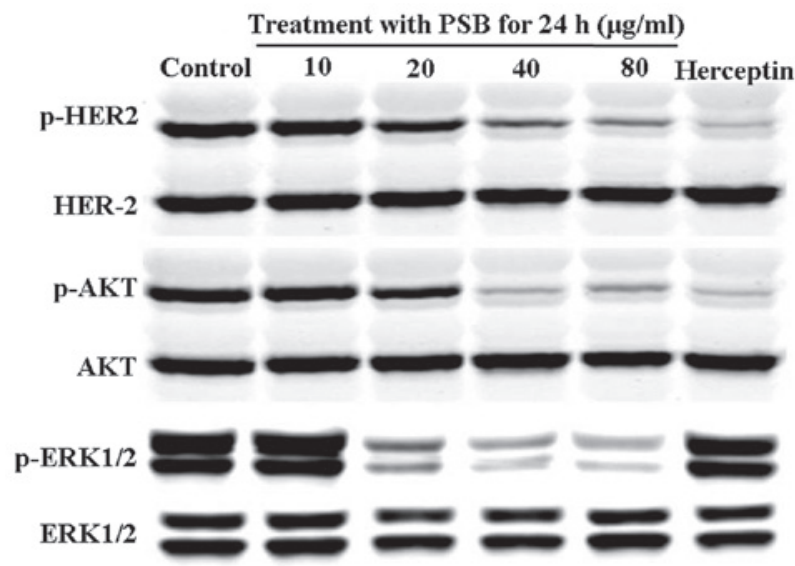

Figure 2. PSB inhibited the expression of p-HER2, p-Akt and p-ERK in Calu-3 cells. The Calu-3 cells were treated with $10,20,40$ and $80 \mu \mathrm{g} / \mathrm{ml}$ PSB for $24 \mathrm{~h}$. The positive control was performed using $10 \mu \mathrm{g} / \mathrm{ml}$ Herceptin. PSB, polysaccharides isolated from Scutellaria barbata D. Don; HER2, human epidermal growth factor receptor 2; p-HER2, phosphorylated HER2; ERK1/2, extracellular signal-regulated kinase 1/2; p-ERK1/2, phosphorylated ERK1/2; p-Akt, phosphorylated Akt.

performed experiments. The statistical analysis was carried out using Student's $t$-test and $\mathrm{P}<0.05$ was considered to indicate a statistically significant difference.

\section{Results}

PSB-induced inhibition of proliferation in Calu-3 cells. The incubation of Calu-3 cells with 10, 20, 40 or $80 \mu \mathrm{g} / \mathrm{ml}$ PSB for $72 \mathrm{~h}$ resulted in a significant increase in the inhibition of cell proliferation, demonstrating that PSB-induced Calu- 3 cell death occurred in a dose-dependent manner. The positive control treatment, consisting of the administration of $10 \mu \mathrm{g} / \mathrm{ml}$ Herceptin, also demonstrated a potent inhibitory effect on Calu-3 cell growth (Fig. 1).

PSB suppression of the HER2 signaling pathway in Calu-3 cells. In order to ascertain whether the expression of p-HER2 in Calu-3 cells would be affected by PSB, the
A
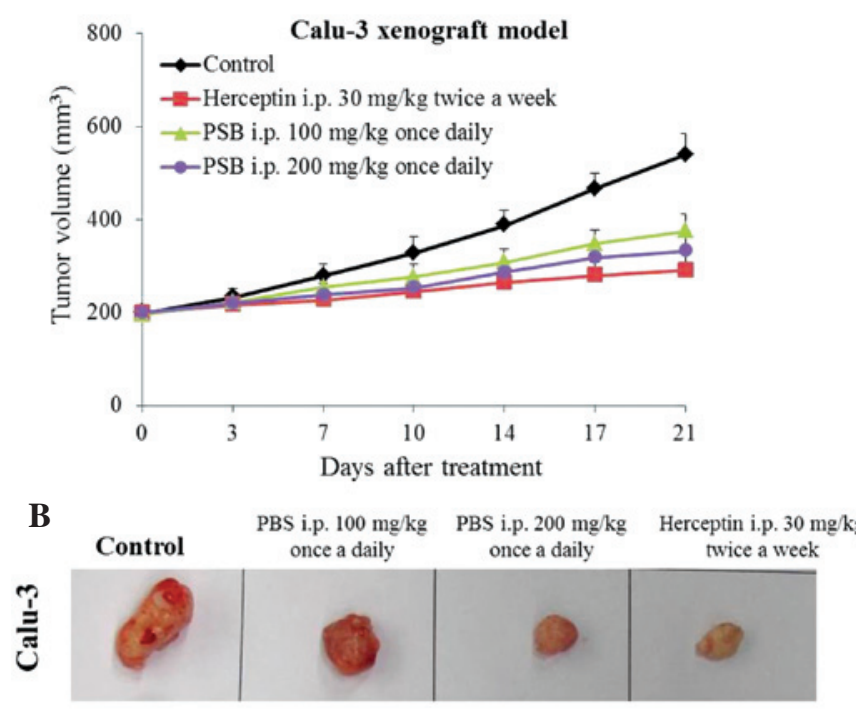

C

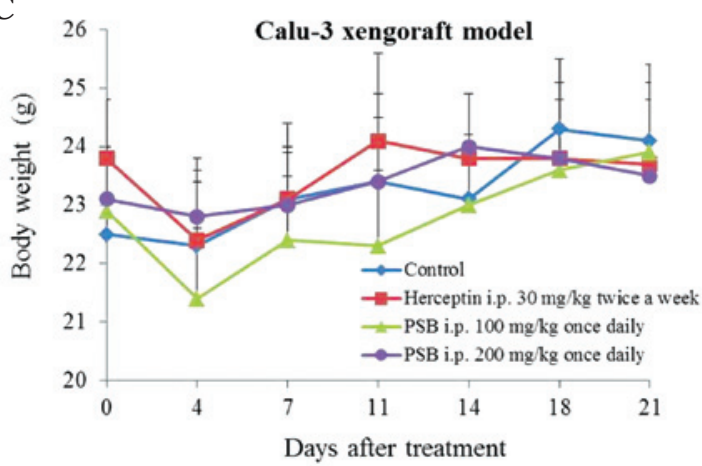

Figure 3. PSB inhibited tumor growth in a Calu-3 xenograft model. (A) Nude Calu-3 tumor-bearing mice were intraperitoneally injected once daily with PSB at the indicated dose or with the control vehicle for $\leq 21$ days. The tumor volume was measured on the indicated days using calipers to yield the mean tumor volume. (B) The Calu-3 cell tumors were resected from nude mice on the last day of treatment. (C) Body weight changes during the process of efficacy study. Treatment with 100 and $200 \mathrm{mg} / \mathrm{kg}$ PSB demonstrated no toxicity in the Calu-3 xenograft model. For the positive control, $30 \mathrm{mg} / \mathrm{kg}$ Herceptin was administered. The data are presented as the mean \pm standard deviated $(\mathrm{n}=8) .{ }^{*} \mathrm{P}<0.05$ and ${ }^{* * *} \mathrm{P}<0.01$ vs. control group. PSB, polysaccharides isolated from Scutellaria barbata D. Don; i.p. intraperitoneally administered.

phosphorylation states of HER2, Akt and ERK were assessed subsequent to $24 \mathrm{~h}$ of treatment with increasing doses of PSB, comprising 10, 20, 40 and $80 \mu \mathrm{g} / \mathrm{ml}$ PSB.

The present results indicated that the expression of p-HER2 in the Calu-3 cells treated with PSB for $24 \mathrm{~h}$ was downregulated in a concentration-dependent manner compared with the vehicle group. High-dose PSB administration $(80 \mu \mathrm{g} / \mathrm{ml})$ was also indicated to completely inhibit p-HER2 expression. The expression of key downstream proteins, including p-Akt and p-ERK, was detected in Calu-3 cells, but PSB was found to demonstrate a concentration-dependent inhibition of the expression of p-Akt and p-ERK compared with the control group. The positive control of $10 \mu \mathrm{g} / \mathrm{ml}$ Herceptin was able to significantly inhibit the expression of p-HER and p-Akt, but only demonstrated a mild inhibitory effect on the expression of p-ERK (Fig. 2).

PSB inhibited tumor growth in the Calu-3 xenograft model. The in vivo efficacy of PSB against tumor growth was 

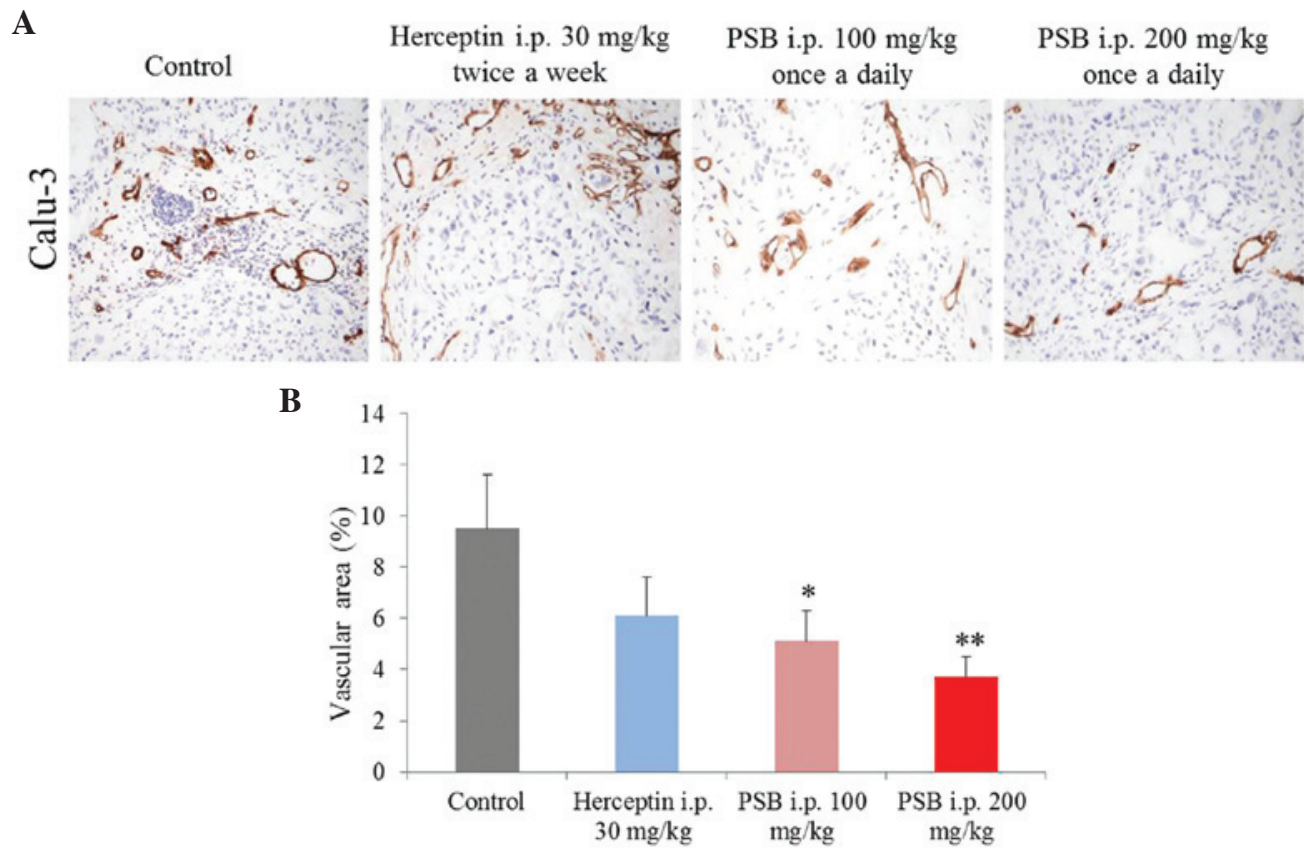

Figure 4. PSB significantly inhibited the expression of CD31 in a Calu-3 xenograft model. (A) Fresh tumors from each group were collected 3 h subsequent to the last treatment with 100 or $200 \mathrm{mg} / \mathrm{kg}$ PSB, and two days subsequent to the last treatment with $30 \mathrm{mg} / \mathrm{kg} \mathrm{Herceptin.} \mathrm{(B)} \mathrm{Representative} \mathrm{CD31} \mathrm{staining} \mathrm{of}$ lung tumors (brown), viewed under a x100 magnification, 60\% center field and vascular area (area of CD31-positive objects per field area x100\%) are shown. ${ }^{*} \mathrm{P}<0.05$ vs. control group. ${ }^{* *} \mathrm{P}<0.01$ vs. control group. PSB, polysaccharides isolated from Scutellaria barbata D. Don; CD31, cluster of differentiation 31; i.p., intraperitoneally administered.

investigated by evaluating its effect on tumor volume in a Calu-3 xenograft model, and the adverse effects of PSB were determined by measuring the body weight gain. As shown in Fig. 3A and B, the administration of PSB significantly decreased tumor volume in a dose-dependent manner compared with the control group $(\mathrm{P}<0.05)$. However, the positive control Herceptin exerted a more potent inhibitory effect on tumor volume in the Calu-3 xenograft model. Throughout the duration of the efficacy study, there was no bodyweight loss observed in any of the groups (Fig. 3C).

PSB inhibits tumor angiogenesis in the Calu-3 xenograft model. Angiogenesis performs an important role in the development and metastasis of cancers. To evaluate the potential anti-angiogenic mechanism of PSB in vivo, the lung adenocarcinoma Calu-3 cell tumors were analyzed by immunostaining for platelet endothelial cell adhesion molecule 1 (CD31). A significant dose-dependent reduction of CD31-positive endothelial cells was observed $3 \mathrm{~h}$ subsequent to the administration of 100 and $200 \mathrm{mg} / \mathrm{kg}$ PSB in Calu-3 cell tumors (Fig. 4A). At the $200 \mathrm{mg} / \mathrm{kg}$ PSB dose, PSB administration resulted in a $60-70 \%$ reduction in CD31-positive microvessels, which was significant compared with the control group $(\mathrm{P}<0.01)$ and indicated that the PSB-induced inhibition of Calu-3 tumor cell growth corresponds with the anti-angiogenic activity (Fig. 4B). However, the positive control of Herceptin only caused a mild, but not significant, reduction in CD31-positive microvessels.

\section{Discussion}

The importance of the phosphatidylinositol 3-kinase (PI3K)-Akt axis in oncogenic signaling is becoming increasingly apparent, particularly in the case of HER2-positive cancer (17). PI3K is responsible for diverse cellular regulation, including cell adhesion, motility, migration, proliferation, reduced apoptosis, anchorage independence and intracellular vesicle trafficking/secretion (18). Akt is the main downstream target of PI3K, and phosphorylation of Akt leads to enhanced cell survival (19). In HER2-amplified cancers, the heterodimer formed by HER2 and kinase-deficient HER3 is a major activator of PI3K-Akt signaling, and when phosphorylated, HER3 directly couples with the p85 subunit of PI3K (20). In the present study, PSB significantly inhibited the growth of HER2-amplified lung adenocarcinoma Calu-3 cell growth in vitro and in vivo. In addition, the results of western blot analysis revealed that p-HER2 and its downstream signaling molecules p-Akt and p-ERK were significantly inhibited by PSB. Therefore, the mechanism of PSB-induced inhibition of Calu-3 tumor cell growth may act through the regulation of the PI3K/Akt and ERK pathways. However, Akt and ERK are downstream signaling molecules not only for HER2, but also for other members of the epidermal growth factor receptor family. Out of these receptors, it is unclear if only HER2 phosphorylaztion was inhibited by $\mathrm{PSB}$, and therefore additional investigation is required.

The proliferation of a network of blood vessels that penetrates into cancerous lesions, supplying nutrients and oxygen to the cells and removing waste products, is termed tumor angiogenesis. This process is initiated by cancerous tumor cells releasing molecules that send signals to the surrounding normal host tissue. This signaling activates certain genes in the host tissue that, in turn, produce proteins to encourage the growth of novel blood vessels (21). Wei et al (22) reported that Scutellaria barbata D. Don inhibited tumor angiogenesis 
via suppression of the Hedgehog pathway in a colorectal cancer HT-29 cell xenograft model. Previous investigation has also revealed that PSB significantly inhibited the cell invasion and migration of human lung cancer 95-D cells in a concentration-dependent manner. The adhesion of 95-D cells to fibronectin was also inhibited by PSB. The expression of C-MET and E-cadherin was significantly down- and upregulated, respectively, in 95-D cells treated with PSB (23). In the present study, it was demonstrated that PSB inhibited tumor angiogenesis in the Calu-3 xenograft model via suppression of the HER2 signaling pathway. However, this result was inconsistent with the findings of Wei et al (22). It is possible that PSB exerts anti-angiogenesis effects in different cancer cell types through the inhibition of various signaling pathways.

In China, TCM has been used for $>1,000$ years to prevent and alleviate a wide variety of diseases. Certain agents used for the treatment of cancer have been derived from TCM $(24,25)$. However, the exact antitumor growth mechanisms of TCM remain unclear, which hinders the usage of TCM in clinical cancer treatment. The present study aimed to explain the mechanism of antitumor effects of PSB in lung cancer cells. The results revealed that PSB not only downregulates the expression of p-HER2 in Calu-3 cells, but also blocks the downstream signaling pathways, including $\mathrm{p}-\mathrm{Akt}$ and $\mathrm{p}-\mathrm{ERK}$. Immunohistochemical analysis in tumor sections revealed that the antitumor efficacy of PSB was mainly associated with anti-angiogenesis. The present study aids the understanding of the antitumor effect of PSB in lung cancer, which may support a breakthrough in the use of TCM for the radical treatment of malignancies.

\section{References}

1. Yarden Y and Sliwkowski MX: Untangling the ErbB signaling network. Nat Rev Mol Cell Biol 2: 127-137, 2001.

2. Yarden Y: The EGFR family and its ligands in human cancer: signalling mechanisms and therapeutic opportunities. Eur J Cancer 37 Suppl 4: 3-8, 2001.

3. Slamon DJ, Clark GM, Wong SG, Levin WJ, Ullrich A and McGuire WL: Human breast cancer: correlation of relapse and survival with amplification of the HER-2/neu oncogene. Science 235: 177-182, 1987.

4. Tanner M, Hollmén M, Junttila TT, et al: Amplification of HER-2 in gastric carcinoma: association with topoisomerase II $\alpha$ gene amplification, intestinal type, poor prognosis and sensitivity to trastuzumab. Ann Oncol 16: 273-278, 2005.

5. Cox G, Vyberg M, Melgaard B, Askaa J, Oster A and O'Byrne KJ: Herceptest: HER 2 expression and gene amplification in non-small cell lung cancer. Int J Cancer 92: 480-483, 2001.

6. She J, Yang P, Hong Q and Bai C: Lung cancer in china: challenges and interventions. Chest 143: 1117-1126, 2013.

7. Schiller JH, Harrington D, Belani CP, Langer C, Sandler A, Krook J, et al: Comparison of four chemotherapy regimens for advanced nonsmall-cell lung cancer. N Engl J Med 346: 92-98, 2002.
8. Weir HK, Thun MJ, Hankey BF, Ries LA, Howe HL, Wingo PA, et al: Annual report to the nation on the status of cancer, 1975-2000, featuring the uses of surveillance data for cancer prevention and control. J Natl Cancer Inst 95: 1276-1299, 2003.

9. Gordaliza M: Natural products as leads to anticancer drugs. Clin Transl Oncol 9: 767-776, 2007.

10. Ji HF, Li XJ and Zhang HY: Natural products and drug discovery Can thousands of years of ancient medical knowledge lead us to new and powerful drug combinations in the fight against cancer and dementia? EMBO Rep 10: 194-200, 2009.

11. Ye CL and Huang Q: Extraction of polysaccharides from herbal scutellaria barbata D. Don (ban-zhi-lian) and their antioxidant activity. Carbohyd Polym 89: 1131-1137, 2012.

12. Yin X, Zhou J, Jie C, Xing D and Zhang Y: Anticancer activity and mechanism of scutellaria barbata extract on human lung cancer cell line A549. Life Sci 75: 2233-2244, 2004.

13. Zhao Z, Holle L, Song W, Wei Y, Wagner TE and Yu X: Antitumor and anti-angiogenic activities of scutellaria barbata extracts in vitro are partially mediated by inhibition of Akt/protein kinase B. Mol Med Rep 5: 788-792, 2012.

14. Suh SJ, Yoon JW, Lee TK, Jin UH, Kim SL, Kim MS, et al: Chemoprevention of scutellaria bardata on human cancer cells and tumorigenesis in skin cancer. Phytother Res 21: 135-141, 2007.

15. Song GC, Yu YJ and Wang XJ: Experiments on antitumor activity and immunological mechanisms of scutellaria barbata polysaccharides. Mode Tradit Chin Med Mater Med 13: 641-643, 2011.

16. Bunn PA Jr, Helfrich B, Soriano AF, Franklin WA, Varella-Garcia M, Hirsch FR, et al: Expression of her-2/neu in human lung cancer cell lines by immunohistochemistry and fluorescence in situ hybridization and its relationship to in vitro cytotoxicity by trastuzumab and chemotherapeutic agents. Clin Cancer Res 7: 3239-3250, 2001.

17. Cho HS, Mason K, Ramyar KX, Stanley AM, Gabelli SB, et al: Structure of the extracellular region of HER2 alone and in complex with the herceptin fab. Nature 421: 756-760, 2003.

18. Moore SM, Rintoul RC, Walker TR, Chilvers ER, Haslett C and Sethi T: The presence of a constitutively active phosphoinositide 3-kinase in small cell lung cancer cells mediates anchorage-independent proliferation via a protein kinase B and p70s6k-dependent pathway. Cancer Res 58: 5239-5247, 1998.

19. Maulik G, Madhiwala P, Brooks S, et al: Activated c-met signals through PI3K with dramatic effects on cytoskeletal functions in small cell lung cancer. J Cell Mol Med 6: 539-553, 2002.

20. Holbro T, Beerli RR, Maurer F, Koziczak M, Barbas CF and Hynes NE: The ErbB2/ErbB3 heterodimer functions as an oncogenic unit: ErbB2 requires ErbB3 to drive breast tumor cell proliferation. Proc Natl Acad Sci USA 100: 8933-8938, 2003

21. Rmali KA, Puntis MCA and Jiang WG: Tumor-associated angiogenesis in human colorectal cancer. Colorectal Dis 9: 3-14, 2006.

22. Wei L, Lin J, Xu W, et al: Scutellaria barbata D. Don inhibits tumor angiogenesis via suppression of hedgehog pathway in a mouse model of colorectal cancer. Int J Mol Sci 13: 9419-9430, 2012.

23. Yang XK, Yang YD, Tang SQ, et al: Inhibitory effect of polysaccharides from scutellaria barbata D. Don on invasion and metastasis of 95-d cells lines via regulation of c-met and e-cad expressions. Tropical J Pharmaceutical Res 12: 517-522, 2013.

24. Zhang J: Clinical values of traditional Chinese medicine in improving the quality of life of cancer patients. Zhong Hua Yi Xue Xie Zuo Za Zhi 7: 735-740, 2000 (In Chinese).

25. Dou YQ, Feng Y and Gao LP: Traditional Chinese medicine treatment for gastrointestinal reaction induced by chemotherapy. Zhong Hua Lin Chuan Yi Xue Za Zhi 6: 11-16, 2005 (In Chinese). 